\title{
ELK DISTRIBUTION AND BEHAVIOR IN CALVING AREAS
}

Mark S. Boyce and John R. Sauer Department of Zoology and Physiology University of Wyoming

\section{Objectives}

The elk (Cervus canadensis nelsoni) of the Grand Teton National ParkSouthern Yellowstone region preferentially utilize fairly-well delineated areas as calving grounds. These areas, which are open sagebrush and bunchgrass-shrub habitats mixed with decadent aspen groves, may be of extreme importance to the elk population insofar as they are the places where the calves are born and spend their first days. It has never been determined how the elk utilize these areas and if disturbances within these areas pose a threat to the elk. Cattle grazing and human use during the spring could act to increase calf mortality by restricting the elk to habitats with less cover for the calves and by separating calves from their dams. Predation of calves by black bear (Ursus americanus) and coyotes (Canis latrans) could increase under these circumstances (Schlegel 1976, McCullough 1969), as could desertion of the calves by their dams, as has been documented for white-tailed deer (Odocoileus virginianus) by White et al. (1972).

This study was designed to evaluate elk use of the calving area located southeast of Moran, Wyoming in Grand Teton National Park. The specific location of the study area is: Range 113 West, Township 44 North, Section 5,6,7,8 and adjacent. Observations were made of elk use of the study area, calf habitat preferences and behavior, and elk responses to disturbances within the study area with the aim of gathering information that would be useful in the management of the elk and their calving grounds.

\section{Procedures}

The elk within the study area were observed daily from May 21 until June 9, 1978. The observer used several routes through the study area to observe the elk and attempted to utilize hilltops throughout the area to spot elk from a distance and thereby minimize the disturbance to the elk. Observations were made using 7 power binoculars and a 20 to 45 power spotting scope.

General trends in elk use of the areas were determined daily by dividing the total number of elk sighted by the amount of time that observations were made. Since observations were made over approximately the same amount of time each day, these estimates of elk use should provide an index of variation in elk use over time. Correlation can also be drawn between 
the elk use of the area and factors that might affect this use. These factors include weather and human and cattle use of the area.

Groups of elk were observed and data were collected on the total number of elk in the group, the group's sex and age composition and activity, their individual distances, their habitat and their relationship to cover. Observations concerning a group were made every 5 minutes and noted on prepared data sheets. If calves were present in or adjacent to a group, their habitat, activity and relationships to the group were noted. Comparisons between groups of elk with calves and groups without calves could then be made. Major emphasis was placed on the observation of elk calf habitat use and the interaction between the calf and its dam with and without disturbances.

Results

The trends in elk use of the study area through the calving period are illustrated in Figure 1. Elk use of the area varied widely and this variation can be attributed to a variety of factors. As the migration of elk progresses, it might be expected that the number of elk in the area increases to a peak and then recedes to a lower number that represents the summer residents. Superimposed on this trend are daily variations in elk use caused by inclement weather and the effect of cattle use and associated human disturbances. May 31, for example, was colder than normal and there was a light snow cover on the ground. Cattle were present in the study area beginning May 31 , and moved further into the study area as time progressed. On June 8 cattle were observed bedded down at midday in an area where elk were observed consistently during the day a week earlier. No elk were noted in this area with the cattle present. Human disturbance also occurred in association with the cattle with ranchers driving into the study area to tend their cattle in clear violation of the restrictions on vehicular traffic in the area. This human disturbance was particularly apparent on June 9 , when trucks and horseback riders were noted in the study area. Elk use of the area was significantly less after May 31, when cattle were first noticed, than before that date.

There were few noted differences in behavior and habitat use between groups with calves and those in which calves were not observed. The most apparent difference was that aggressive interactions between individuals within the group increased when calves were present. During the day calves generally remained hidden in the sage adjacent to the group, becoming more active as the group moved or engaged in active grazing in the mornings and evenings. When a group was disturbed, the calves either remained hidden or ran with their dams, the variation in behavior probably due to the age of the calf (Altmann 1963). Hiding calves when approached either flushed and ran or remained still. This variation in behavior may also be correlated with age.

Bobcats (Lynx rufus) and coyotes were noted in the study area, with coyotes being by far the most visible potential elk calf predator. Elk were noted to chase coyotes from the vicinity of their calves on several 
occasions, at one point following the coyote for approximately 200 yards. Black bear were not noted in the study area, although they were present in the adjacent forests.

Cow elk that reacted to my presence by leaving their calves and moving to more dense cover remained away from their calves for at least 4 hours. The cows' absence has obvious effects on elk calf survival when opportunistic predators such as coyotes are present.

Two births of calves were observed on June 4 and June 5. Both occurred in grassy spots in open aspen stands on gentle slopes. The cow flushed soon after the calf was born in one case, and the calf remained lying after several attempts to rise. The cow did not return in 3 hours of observation. The calf was gone the next day. The other cow alternately nursed and groomed the calf, and left the area with the calf after approximately 1.5 hours. Detailed reports of the cow-calf interactions will not be presented here.

\section{Conclusions}

Elk use of the study area seemed to decrease as cattle use and associated human disturbances increased. Whether this change in elk use was due to these factors or was caused by the patterns of the elk migration is not clear. In addition to this, it was noted that calves preferentially hid in sagebrush areas. When disturbed, dams left the calves hiding in these areas and did not return for long periods of time. Without their dam to protect them these calves were vulnerable to predation and the possibility of desertion by the dams also existed. Disturbance of the elk within these areas during the spring could have deleterious effects by forcing the elk into unfavorable habitats where less cover exists for calves and by increasing calf mortality through predation and desertion.

\section{Literature Cited}

Altmann, M. 1963. Naturalistic studies of maternal care in moose and elk. Pp. 233-253 in H. L. Rheingold, ed., Maternal Behavior in Mammals. John Wiley, New York. 849pp.

McCullough, D. R. 1969. The tule elk: its history, behavior, and ecology. Univ. of Calif. Publ. Zool. 88. 209pp.

Schlegel, M. 1976. Factors affecting calf elk survival in north-central Idaho--A progress report. Proc. West. Assoc. State Game and Fish Commissioners 56: 342-355.

White, M., F. F. Knowlton and W. C. Glazener. 1972. Effects of damnewborn fawn behavior on capture and mortality. J. Wildl. Manage. $36(3): 897-906$. 
$-18-$

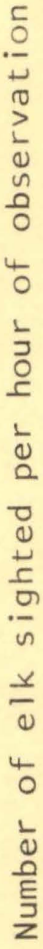

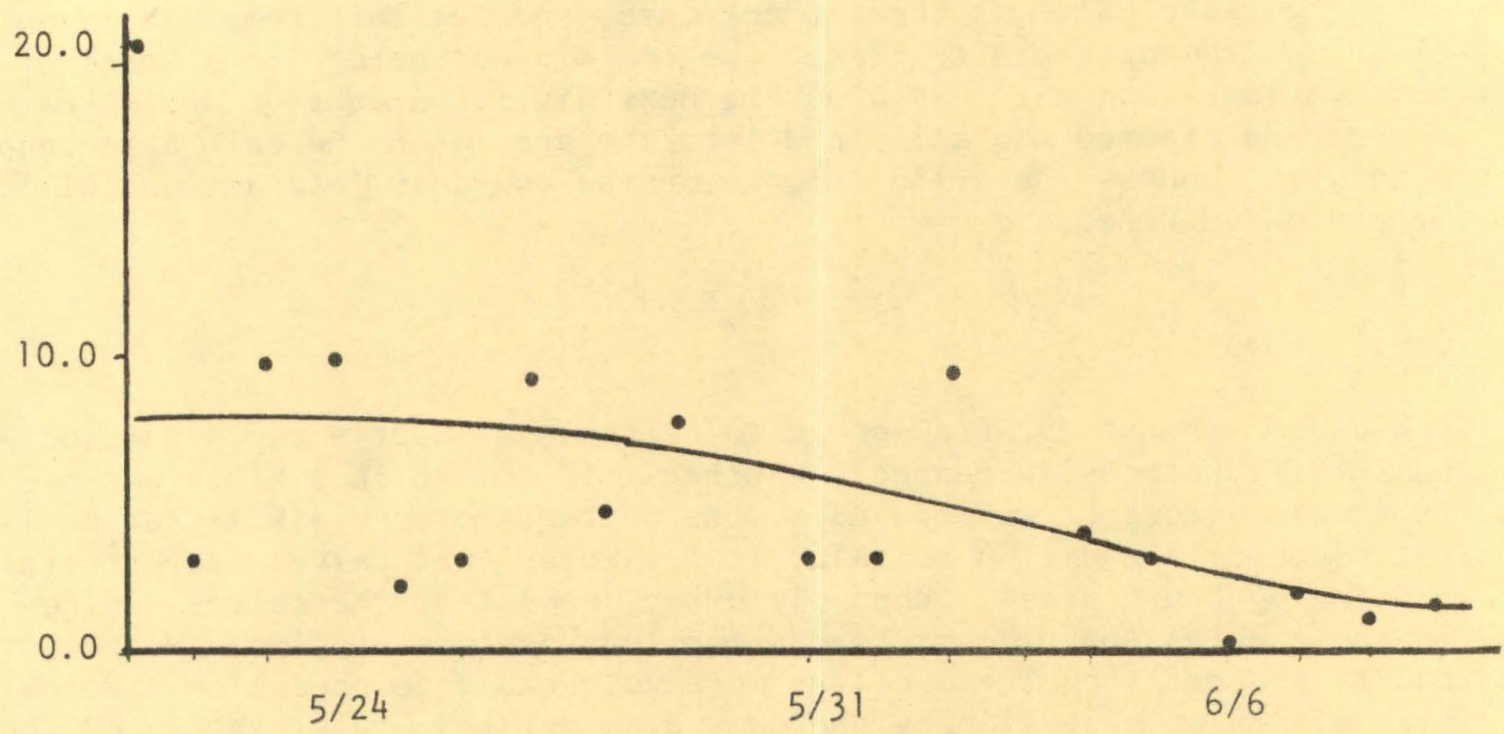

$\uparrow$

Date

Figure 1. Trend in elk use of the study area between 21 May and 9 June 1978. Curve fitted by eye. Arrow indicates the onset of cattle grazing. 